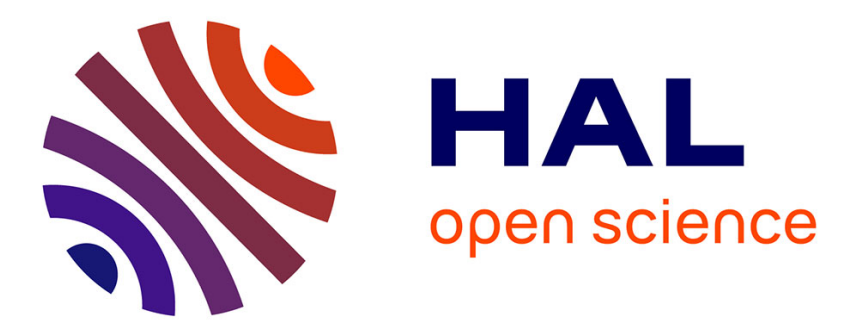

\title{
Investigating the Potential in Reconfigurable Manufacturing: A Case-Study from Danish Industry
}

Ann-Louise Andersen, Thomas D. Brunoe, Kjeld Nielsen

\section{To cite this version:}

Ann-Louise Andersen, Thomas D. Brunoe, Kjeld Nielsen. Investigating the Potential in Reconfigurable Manufacturing: A Case-Study from Danish Industry. IFIP International Conference on Advances in Production Management Systems (APMS), Sep 2015, Tokyo, Japan. pp.274-282, 10.1007/978-3-31922756-6_34 . hal-01417488

\section{HAL Id: hal-01417488 \\ https://hal.science/hal-01417488}

Submitted on 15 Dec 2016

HAL is a multi-disciplinary open access archive for the deposit and dissemination of scientific research documents, whether they are published or not. The documents may come from teaching and research institutions in France or abroad, or from public or private research centers.
L'archive ouverte pluridisciplinaire HAL, est destinée au dépôt et à la diffusion de documents scientifiques de niveau recherche, publiés ou non, émanant des établissements d'enseignement et de recherche français ou étrangers, des laboratoires publics ou privés. 


\title{
Investigating the Potential in Reconfigurable Manufacturing: a Case-study from Danish Industry
}

\author{
Ann-Louise Andersen, Thomas D. Brunoe and Kjeld Nielsen \\ Department of Mechanical and Manufacturing Engineering, Aalborg University, Denmark \\ ala@m-tech-aau.dk
}

\begin{abstract}
In today's global manufacturing environment, manufactures must respond to the challenges of quickly adopting new technologies and provide an increasing number of product varieties, while continuously increasing costefficiency. Reconfigurable manufacturing systems meet these challenges through rapid and efficient changes in functionality and capacity. The purpose of this paper is to investigate a practical approach for evaluating the potential of reconfigurability in manufacturing companies, through a case-study in Danish industry. In this approach, historical production data is analyzed and focus is explicitly on capacity savings, which makes it applicable for decision support in companies that are in a transition towards becoming reconfigurable.
\end{abstract}

Keywords: Reconfigurable manufacturing, Reconfigurability, Changeable manufacturing, Reconfigurability potential, RMS potential

\section{Introduction}

Short product life-cycles, uncertainty in product demand, and pressure for maintaining cost-efficiency are conditions which manufacturing companies need to cope with, in order to remain competitive in today's global market [11]. Therefore, manufacturers need to find solutions for fast adaption of resources to varying market requirements, without significant losses in productivity [4]. The reconfigurable manufacturing system (RMS) is one of the means to this, through its ability to be continuously upgraded and changed, instead of being dedicated and optimized for one specific product model and demand situation [7]. Moreover, as the RMS is designed to contain the exact functionality and capacity needed to produce a given product family, the issues of flexible manufacturing in regards to excess flexibility, low production rate, and low return on investments are avoided [7]. For that reason, the reconfigurable manufacturing concept has been widely labelled the manufacturing paradigm of the future [11].

\subsection{Literature Review}

Reconfigurable manufacturing meets challenges in the current competitive environment that traditional manufacturing systems are not able to. However, the 
implementation of reconfigurability is still a significantly challenging task with several theoretical and practical problems [6], [8]. Currently, RMS research is widely concerned with optimization techniques for configuration selection, planning and scheduling techniques, and the development of reconfigurable machines. An area that has received only limited attention is the evaluation of RMS potential, even though determining the need for reconfigurability and justifying its investment is one of the first crucial steps in its implementation [1], [3].

In existing research, pre-design evaluations of a RMS is currently carried out through economic justification models. Kuzgunkaya and ElMaraghy [5] present an RMS evaluation model using a fuzzy multi-objective optimization approach incorporating both economic and strategic objectives, such as flexibility and responsiveness. Amico et al. [2] propose a model that compares system alternatives based on traditional net present value and real options analysis. Singh et al. [9] and Abdi and Labib [1] apply fuzzy analytical hierarchy processing logic for the selection of manufacturing systems based on different criteria, such as responsiveness, product cost, operator skill, and convertibility. The common denominator of these contributions is the selection of manufacturing system alternatives based on an economic justification and a quantitative assessment of several different criteria. Despite the significance of these models, their practical applicability can be questioned. First of all, estimating anticipated costs and other quantitative criteria related to each system alternative may represent a highly difficult and time-consuming task in many companies. Secondly, these aforementioned models represent advanced decision support tools and conceptual selection of the best manufacturing system. However, manufacturing system selection also depends heavily on practical considerations, which complicates the use of these models in reality. Moreover, these models do not have explicit focus on the potential of RMS, but rather on justifying its implementation from an economic perspective.

\subsection{Research Question}

One potential reason for the limited research in how to evaluate RMS potential, may be the difficulty and lack of experience in proving RMS advantages, and the general uncertainty in industry about what reconfigurability actually is [3], [8]. This further emphasizes that when determining the need for reconfigurability in a given company, focus should be on highlighting easily apprehensible aspects and on increasing knowledge of RMS main benefits. However, the aforementioned current approaches to justifying RMS investment do not support this, as they focus heavily on economic evaluation and require much effort to apply, which is unlikely in companies that do not yet fully perceive and understand the real benefits of manufacturing reconfigurability.

Based on these considerations, the following research question is formulated: how can the potential in reconfigurable manufacturing systems be determined for manufacturing companies using information and data that is readily available and how can the results be interpreted?

In the following section, the method applied to answering this question and the casecompany and related data applied for determining RMS potential is described. 


\section{Methodology}

In order to address the research question stated above, there are two main concerns. The first is the development of a method for evaluating the potential in reconfigurable manufacturing and the second is how to apply it and interpret the results. In order to do this, a case from Danish industry that produces electronic products for a water utility company is applied. This factory produces a large variety of different electronic products that in the latest years have been subject to numerous upgrades. These product generations, both minor and larger, have resulted in completely new and dedicated final assembly lines with no reuse from previous generations of assembly systems. Therefore, this factory is an interesting case for investigating RMS potential, as it exemplifies the traditional approach to manufacturing system design which is dedicated manufacturing lines with decreasing life-time due to rapid product changes.

\subsection{Evaluating RMS Potential}

Determining the potential in designing and operating a RMS, requires that focus is on the distinguishing feature of the reconfigurable system compared to the dedicated system, which is that its configuration can be changed over time, in order to provide the exact functionality and capacity needed by the market [4]. In order for a system to be reconfigurable, it must possess the characteristics of capacity scalability, function convertibility, and customized flexibility, while modularity, integrability, and diagnosability are supporting characteristics that enables reconfigurability [4]. Therefore, when evaluating RMS potential, focus should be explicitly on these three essential characteristics and the benefits of applying them.

The benefit of scalable capacity is that demand and supply can be matched gradually, thereby avoiding situations with either excess capacity or unmet demand. In contrary, dedicated lines have rigid structures that do not allow for capacity change in accordance with market change, product upgrade, and product maturity curves [4]. The benefit of convertibility is that the life of a RMS is longer than the life of a dedicated line, as it consists of different periods satisfying different demand scenarios, in terms of product variety and product mix. Moreover, as a RMS has customized flexibility, it is able to produce all parts or products within a family. In order to summarize these RMS benefits, the following proposition can be formulated: in a reconfigurable manufacturing setting, capacity is lower than in the situation where products or parts have dedicated systems, as several different product generations and varieties can be produced simultaneously through reconfigurations.

Narrowing attention to this proposition makes it possible to evaluate RMS potential based on the capacity differences between initial dedicated setups and future RMS setups, using readily available historical data on capacities and production output from industrial companies. Nevertheless, evaluating such capacity differences requires both that the actual dedicated setup is analysed and that it is compared to a fictional RMS setup based on the same historical data. Therefore, developing a fictional RMS setup is the key concern in the approach to evaluate RMS potential developed in this paper. 
In order to develop a RMS scenario based on actual historical data on production output of different product varieties and product generations, it is presumed that a number of reconfigurable lines are used, which can produce several product generations and varieties simultaneously. Moreover, as each reconfigurable line by definition is modular, the scenario is scalable by adding and extracting lines to the reconfigurable setup. Having a number of reconfigurable lines as the foundation for the reconfigurable scenario, the key task is to distribute the actual historical production output to the RMS lines, thereby dividing the historical data into different configuration periods, which represent the final RMS scenario.

\subsection{Data}

In order to test this approach to evaluate RMS potential, the aforementioned electronics factory is applied as a case. The foundation for evaluating RMS potential in this case is historical data on production output and capacities of production systems related to a specific electronics product family. More specifically, seven-year production output data from the case-company's ERP system for all varieties and generations within the product family is extracted and used for the analysis. In the seven-year period that is considered here, a total of four product upgrades have occurred resulting in four product generations.

The production area in focus is the final assembly of the electronics products. In this area, production lines are purely dedicated, meaning that all generations are produced on separate lines. Despite the fact that only minor changes have happened between each generation and all variants belong to the same product platform, there is currently no reuse of production equipment. Moreover, there are separate dedicated production lines for product variants within the same generation. In fact, the product family contains two main groups of variants that are sold to different market segments, here denoted as type A and type B. Each product generation contain both groups of variants, besides generation 2 that only contains type $\mathrm{B}$. The two groups of variants have the same overall functionality, but are produced on separate dedicated production lines. Therefore, in the following capacity analysis of the current dedicated setup, these two types will be treated separately.

\section{$3 \quad$ Results}

The first step in investigating RMS potential in the case, is to compare actual production output on each production line with the actual available capacity. In Fig. 1 and Fig. 2, the results of this analysis are depicted. It is evident that in the seven-year period that was analyzed, the total production capacity far exceeds the actual output. In fact, only a third of the available capacity is used on average for both type A and B equipment. This significant excess in capacity results from inability to gradually scale capacity, but also from having rigid dedicated lines that can only be used for one generation or only a part of the whole product family. 


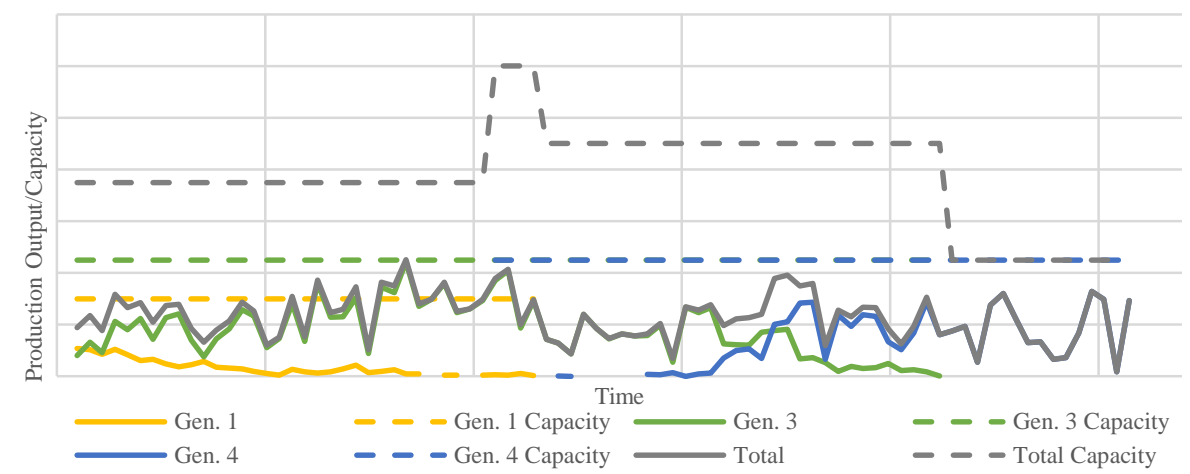

Fig. 1. Analysis of capacity and output of type A generations

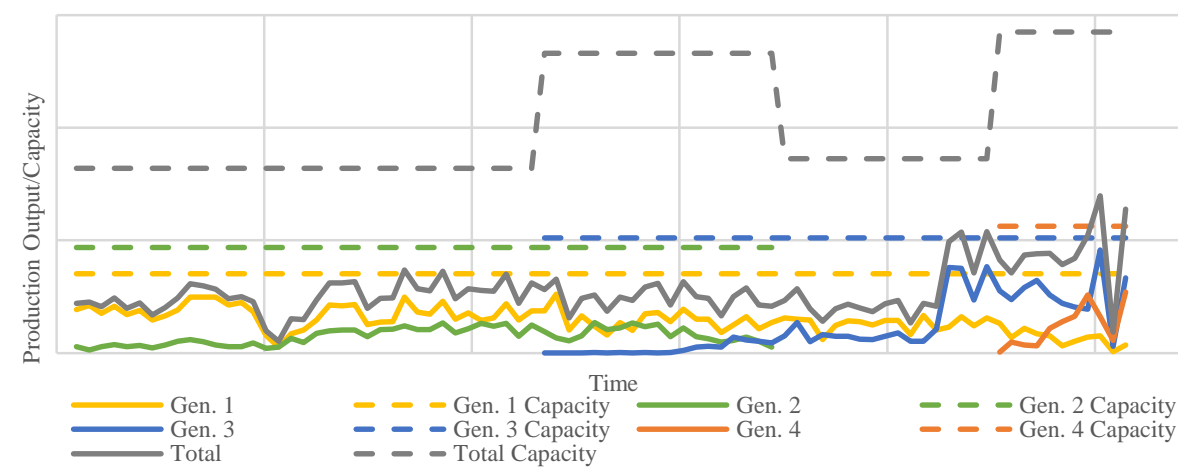

Fig. 2. Analysis of capacity and output of type B generation

The significant capacity excess in the current dedicated setup indirectly indicates that there is a potential in changing the approach to reconfigurable manufacturing. However, in order to explicitly evaluate this, the following RMS scenario is developed. In this scenario, the same seven-year historical data is divided into different configuration periods, based on significant changes in demand volume, product phaseouts, or product introductions. In each configuration period, the reconfigurable lines have different setups and the capacity of the overall setup is scalable. Moreover, it is reasonable to include both type A and B groups of variants in the same setup, as RMSs by definition are able to produce a whole product family in contrary to dedicated lines. Therefore, in the scenario it is assumed that a number of RMS lines with fixed capacity is utilized, but that the overall system is scalable by adding and extracting RMS lines. The fixed capacity of the RMS lines and the number of lines is determined in cooperation with the case company.

In order to make the RMS scenario as realistic as possible, the following restrictions have been developed in cooperation with the case-company. First of all, the total capacity of the RMS lines should be sufficient to produce the same output in terms of volume and product types as in the historical data. However, up to two periods in a row with insufficient capacity is allowed, if the previous two months have sufficient capacity for covering the deficit or a RMS line in the same period produced a similar 
generation and has sufficient capacity. This restriction relates to the fact that some production planning and inventory can be assumed in the RMS scenario, and that both type A and B product can be produced simultaneously. Secondly, it is decided that between two consecutive configuration periods, it is only possible to change functionality of the RMS line from one product generation to the next. This means that it is only possible to change from one generation to the third over more than two configuration periods. This restriction relates to the convertibility of the system, which should match the actual possibilities in the case. In Fig. 3, the resulting reconfigurable scenario and a comparison of total dedicated and RMS capacity are depicted. Table 1 summarizes each configuration of the RMS setup. It is evident that considerable capacity savings will follow from changing the current dedicated lines and applying reconfigurability. In the seven-year period that is analyzed, a capacity reduction of approximately $50 \%$ is possible if the current setup is changed to a reconfigurable setup consisting of up to eight RMS lines. This setup contain only 3 out of 84 periods with a capacity deficit that cannot be satisfied by the above mentioned rules. The capacity reduction results from having manufacturing lines that are able to produce the whole product family and able to be reconfigured rather than replaced. In the following section, these results and the related assumptions are discussed.

Table 1. Configuration Periods for RMS Scenario

\begin{tabular}{lcccccc}
\hline & Conf. 1 & Conf. 2 & Conf. 3 & Conf. 4 & Conf. 5 & Conf. 6 \\
\hline Periods & 19 months & 18 months & 19 months & 13 months & 10 months & 6 months \\
\hline Line 1 & Gen. 1A & Gen. 1A & Gen. 2B & Gen. 3A & Gen. 3B & Gen. 3B \\
\hline Line 2 & Gen. 3A & Gen. 3A & Gen. 4A & Gen. 4A & Gen. 3B & Gen. 3B \\
\hline Line 3 & Gen. 3A & Gen. 3A & Gen. 3A & Gen. 4A & Gen. 4A & Gen. 4A \\
\hline Line 4 & Gen. 1B & Gen. 1B & Gen. 1B & Gen. 1B & Gen. 1B & Gen. 1B \\
\hline Line 5 & Gen. 1B & Gen. 1B & Gen. 1B & & Gen. 4A & Gen. 4A \\
\hline Line 6 & Gen. 2B & Gen. 2B & & Gen. 3B & Gen. 3B & Gen. 3B \\
\hline Line 7 & & Gen. 3A & Gen. 3A+B & Gen. 3A & Gen. 4B & Gen. 4B \\
\hline Line 8 & & & & Gen. 4B \\
\hline
\end{tabular}

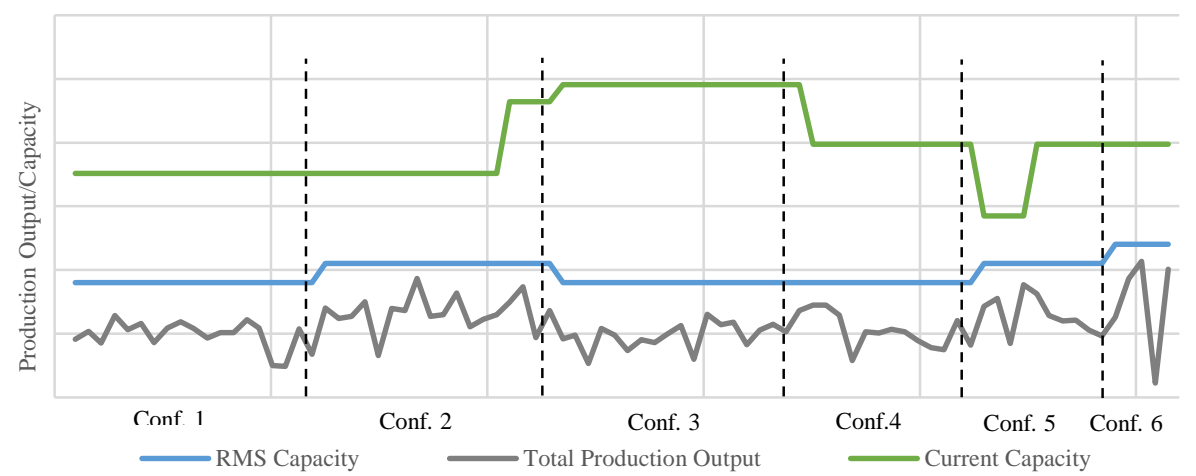

Fig. 3. RMS Scenario and Comparison of Total Current and RMS Capacity 


\section{Discussion}

In the approach to evaluate RMS potential developed in this paper, there are three main assumptions. The first assumption concerns the ramp-up period after each reconfiguration. If the RMS lines are not able to be quickly reconfigured to a new product, significant losses in output volume will follow, which will reduce the RMS benefits. In the RMS evaluation, volume losses or downtime due to reconfigurations have not been incorporated, as this would have required more thorough investigations on the changes between generations and the technical aspects of the production conversion. However, in order to further explore RMS potential, it is necessary to investigate systematic ramp-up reduction in the RMS environment. Currently, there are several contributions in research on general problems and performance consequences encountered in the ramp-up period [10]. However, research is limited in regards to ramp-up and the specific challenges in modular and reconfigurable manufacturing systems, which seems like an important future research topic.

The second main assumption is related to the cost and effort of refitting the manufacturing line to new product generations. When potential capacity savings from implementing reconfigurability are indicated above, it is assumed that product generations have sufficient commonality to be treated by the same production processes and equipment. In the specific case, this is a valid assumption due to a minor degree of change between generations that are built on the same product platform. However, when determining RMS potential in further manufacturing cases, this subject should be considered simultaneously.

The third assumption is related to the decision of RMS line capacities. In the case, each line in the RMS scenario have equal and constant capacity, which is determined in cooperation with the case company. However, in reality the decision of system and line capacities is much more complicated and involves levels beyond what is covered in this paper. In other words, the scalability of the entire reconfigurable scenario developed here is achieved simply through adding or extracting RMS lines, while functional convertibility is assumed to be achieved on each line by changing its modules. In reality, reconfigurability can be achieved at numerous levels, e.g. on system, cell, and station level, which means that scalability and convertibility can be realized at more levels than considered in this paper. Therefore, an interesting topic for future research would be to investigate the decision of on which levels to realize reconfigurability and how to effectively determine the capacity of the system.

The approach developed in this paper represents a pre-design activity that can be applied as decision support in companies that are in a RMS transition. The RMS potential is indicated by using historical data, which is considered a useable indicator for future potential. In this regard, it should be emphasized that the development of the RMS scenario is carried out with full predictability in the production output in each period. Thus, this approach is not intended as a means for configuring future reconfigurable lines, but rather as a means to highlighting performance improvement that could have been achieved through the application of manufacturing reconfigurability. In addition, this approach to evaluate RMS potential do not substitute 
the economic evaluation models that are present in the current body of RMS research, but rather represents a practical first attempt to evaluate the main RMS benefits.

\section{Conclusion}

One of the crucial steps in the implementation of reconfigurable manufacturing is the evaluation of its potential in different manufacturing settings. Therefore, the aim of this paper is to investigate a method for determining RMS potential, using data that is readily available in manufacturing companies. The approach to this focuses on potential capacity savings resulting from manufacturing systems where several different product generations and varieties can be produced simultaneously, through reconfigurations. Through a case-study from Danish industry, the approach is applied and historical data on capacities and production output are analyzed, and a reconfigurable manufacturing setup is developed. Moreover, through this approach to evaluating RMS potential, knowledge of reconfigurability is increased in the evaluated manufacturing company, which makes it highly applicable for decisions support in companies that are in a RMS transition.

\section{References}

1. Abdi, M. R., \& Labib, A. W.: Feasibility Study of the Tactical Design Justification for Reconfigurable Manufacturing Systems using the Fuzzy Analytical Hierarchical Process. International Journal of Production Research, 42 (2004) 3055-3076

2. Amico, M., Asl, F., Pasek, Z. et al.: Real options: an application to RMS investment evaluation. In: Dashcenko, A.I. (ed.) Reconfigurable Manufacturing Systems and Transformable Factories, pp. 675-693. Springer (2006)

3. Heisel, U., \& Meitzner, M.: Progress in reconfigurable manufacturing systems. In: Dashcenko, A.I. (ed.) Reconfigurable Manufacturing Systems and Transformable Factories, pp. 47-62. Springer (2006)

4. Koren, Y.: The global manufacturing revolution: Product-process-business integration and reconfigurable systems. John Wiley \& Sons (2010)

5. Kuzgunkaya, O., \& ElMaraghy, H.: Economic and Strategic Perspectives on Investing in RMS and FMS. Int. Journal of Flexible Manufacturing Systems, 19 (2007) 217-246

6. Malhotra, V., Raj, T., Arora, A.: Evaluation of Barriers Affecting Reconfigurable Manufacturing Systems with Graph Theory and Matrix Approach. Materials and Manufacturing Processes, 27 (2012) 88-94

7. Mehrabi, M. G., Ulsoy, A. G., Koren, Y.: Reconfigurable Manufacturing Systems: Key to Future Manufacturing. Journal of Intelligent Manufacturing, 11 (2000) 403-419

8. Rösiö, C., \& Säfsten, K.: Reconfigurable Production System Design-theoretical and Practical Challenges. Journal of Manufacturing Technology Mgt., 24 (2013) 998-1018

9. Singh, R., Khilwani, N., Tiwari, M.: Justification for the Selection of a Reconfigurable Manufacturing System: A Fuzzy Analytical Hierarchy Based Approach. Internationa Journal of Production Research, 45 (2007) 3165-3190

10. Surbier, L., Alpan, G., Blanco, E.: A Comparative Study on Production Ramp-Up: Stateof-the-Art and New Challenges. Production Planning \& Control, 25 (2014) 1264-1286

11. Wiendahl, H., ElMaraghy, H. A., Nyhuis, P. et al.: Changeable ManufacturingClassification, Design and Operation. CIRP Annals-Mfg. Technology, 56 (2007) 783-809 